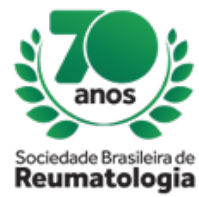

\title{
THE PREVALENCE OF INFLAMMATORY BACK PAIN IN MEDICAL STUDENTS
}

Isa Cavalcanti Martildes (Universidade de Fortaleza, FORTALEZA, CE, Brasil), Louise Cavalcanti Salles (Unichristus, FORTALEZA, CE, Brasil), Beatriz Lis Soares Holanda (Universidade de Fortaleza, FORTALEZA, $\mathrm{CE}$, Brasil), Maria Paula Lopes Ponte Prado (Universidade de Fortaleza, FORTALEZA, CE, Brasil), Sara Vasconcelos de Sousa (Universidade de Fortaleza, FORTALEZA, CE, Brasil), Kirla Wagner Poti Gomes (Universidade de Fortaleza e Hospital Geral de Fortaleza, FORTALEZA, CE, Brasil)

\section{BACKGROUND}

Inflammatory back pain (IBP) is the earliest finding of seronegative spondyloarthritis and represents about $6,7 \%$ of all back pain. The most recent and most used criteria for IBP are those of the ASAS: if the patient has low back pain for more than 3 months and has 4 out of 5 parameters (age of back pain onset $<40$ years, gradual onset, improvement with exercise, no improvement with rest and back pain at night which improves upon getting up), he is classified as having IBP with $79,6 \%$ of sensibility and $72,4 \%$ of specificity. The purpose of this study was to analyze the prevalence of IBP using ASAS criteria in medical students.

\section{MATERIALS AND METHODS}

Descriptive cross-sectional study, based on the results of an online questionnaire of Google Forms platform in medical students of state of Ceará.

\section{RESULTS}

113 medical students answered the questionnaire, $68.1 \%$ of which were female and only one was over 40 years and the average age was between $20-25$ years. None of the students had diagnosed inflammatory disease, $70 \%$ had already experienced low back pain and, of these, $8.9 \%$ presented it daily. Regarding the use of non-steroidal anti-inflammatory drugs, 34.1\% had already used it and, of these, $70.3 \%$ reported improvement. In addition, 32.9\% reported gradual onset, 30.3\% improved with physical activity, $17.7 \%$ had alternating buttock pain, $12.6 \%$ did not improve with rest, $7.5 \%$ presented morning stiffness and $34,2 \%$ stated that the pain interfered with daily activities. When the questions for IBP were evaluated together, it was observed that $2(1,7 \%)$ students fulfilled the ASAS criteria with 4 out of 5 parameters. Two other students had 3 out of 5 , which does not completely exclude the condition.

\section{CONCLUSION}

The prevalence of low back pain in medical students was high, with almost $10 \%$ having it daily, and more than a third believing that pain interfered with daily activities. Only two participants (1,7\%) met ASAS criteria for IBP, and although this prevalence is low, it is important to be remembered in order to make an early diagnosis of spondyloarthritis, avoiding complications of the disease. 